\title{
A resistência poética de Ferreira Gullar
}

\section{Cimara Valim de Melo*}

Resumo: O enfoque deste artigo dirige-se à análise de produções poéticas de Ferreira Gullar, publicadas nas décadas em que perdurou o regime ditatorial no Brasil. A resistência desse múltiplo escritor à fragmentação do mundo existente ao seu redor, principalmente nas décadas de 1960 e 1970, dá-se não apenas através de seu viver revolucionário, ferrenhamente crítico, mas principalmente por meio de sua produção poética recheada de ousadia, perigo e liberdade, com a publicação dos livros Dentro da noite veloz (1975), Poema Sujo (1976) e Na vertigem do dia (1980). Testemunha de uma realidade contraditória e injusta, Gullar recriou em seus versos a lucidez e a revolta frente a um tempo vazio de sentido. Ultrapassou as fronteiras literárias, semeando a esperança em momentos de perseguição política e de crises sociais.

Palavras-chave: Poesia Brasileira do século XX; Ferreira Gullar; Ditadura militar.

\begin{abstract}
This article brings into focus the analysis of Ferreira Gullar's poetic works, issued during the dictatorial years in Brazil. The resistance expressed by this multiple writer against the fragmentation of the world surrounding him, especially during the decades of 1960 and 1970 , is displayed not only through his revolutionary and extremely critical personality, but also through his poetry, filled with boldness, danger, and freedom. These features are all to be found in books such as Dentro da noite veloz (1975), Poema Sujo (1976), and Na vertigem do dia (1980). As a witness of a contradictory and unfair reality, Gullar's poems recreated the feelings of lucidity and uprising towards such hallow and meaningless years. He has gone beyond literary boundaries, spreading hope in times of political abuse and social crises.
\end{abstract}

Keywords: Brazilian Poetry in the XX century; Ferreira Gullar; Military Dictatorship.

\section{Este é tempo de partido, tempo de homens partidos [...] O poeta declina de toda responsabilidade na marcha do mundo capitalista e com suas palavras, intuições, símbolos e outras armas promete ajudar a destruí-lo como uma pedreira, uma floresta, um verme. \\ CARLOS DRUMMOND DE ANDRADE}

Digo adeus à ilusão mas não ao mundo. Mas não à vida, meu reduto e meu reino.

Do salário injusto, da punição injusta, da humilhação, da tortura,

\footnotetext{
* Cimara Valim de Melo é mestre em Literatura Brasileira pela Universidade Federal do Rio Grande do Sul e professora da Rede Pública de Ensino do Rio Grande do Sul.
} 
do terror,

retiramos algo e com ele construímos um artefato

um poema

uma bandeira

FERREIRA GULLAR

A poesia moderna brasileira, principalmente após a II Guerra Mundial, sofre uma de suas maiores crises de significados, causada pela perda da imagem do mundo - disperso e fragmentado -, pela massificação da cultura e pela coisificação do homem. Esse mosaico que se forma faz com que ela resista ao empobrecimento da linguagem, causando o que George Steiner chama de "repúdio à palavra". Para ele, a literatura representa apenas uma pequena parte da crise universal. Ela se torna a expressão crítica da negação do mundo e de si mesma, do dilaceramento do ser e da busca de sentido.

Há uma indicação generalizada, embora ainda só definida de forma vaga, de uma certa exaustão de recursos verbais na civilização moderna, de uma brutalização e desvalorização da palavra nas culturas de massa e na política de massas contemporâneas. O que mais se pode fazer? Como aquilo que é inovador e penetrante o suficiente para ser dito poderá ser ouvido em meio ao clamor da inflação verbal? (STEINER, 1988, p. 65)

A modernidade vê-se tomada por uma enxurrada de idéias, de imagens, de comunicação superficial, que abafa a poesia, deixando-a sem rumo. A desumanização da sociedade conduz à desumanização da linguagem. Os poetas modernos buscam, a partir dessa realidade amarga, (re)humanizar a sociedade através da literatura e, ao mesmo tempo, resistir à falta da linguagem pela própria poesia. Segundo Bosi,

a ficção mais recente tem resistido à pressão conjugada da tecnolatria, da massificação e do totalitarismo interno. Uma literatura penetrada de pensamento, uma literatura que faz da autoanálise, da pesquisa do cotidiano (rústico, urbano, suburbano, marginal), do sarcasmo e da paródia o seu apoio para contrastar o sentido das ideologias dominantes; uma literatura que vive em tensão com os discursos da rotina e do poder; e que se faz e se refaz no nível da representação arduamente trabalhada pela linguagem. (BOSI, 1988, p. 125)

A diversidade da poesia torna-a contradição em um tempo desumano e opaco. Do mesmo modo que ela se fecha ao injusto processo capitalista, à selvageria sócio-políticoeconômica, abre-se a interpretações múltiplas pela busca de sentido. Mais do que nunca, a poesia é matéria descartável, dessacralizada, e o poeta encontra no lixo social a essência de seu fazer poético, o modo para percorrer o perigoso labirinto da palavra. Ela se suja com a consciência da hipocrisia humana e se diversifica ao buscar a negação da modernidade e de si mesma, gerando uma constante mutação, analisada por Octavio Paz:

O tempo moderno é o tempo da cisão e da negação de si mesmo, o tempo da crítica. A modernidade identificou-se com a mudança, identificou a mudança com a crítica e as duas com o progresso. A arte moderna é moderna porque é crítica. Sua crítica se estendeu em duas direções contraditórias: foi uma negação do tempo linear da modernidade e foi uma negação de si mesma. (PAZ, 1984, p. 189) 
O caráter de negação, crítica e mudança da arte incorporou-se ao estilo de diversos escritores, os quais interligaram à função dessa mesma arte uma intensa preocupação social. Mais que representar a beleza estética, a arte moderna vislumbra resistir à desumanização.

O cenário brasileiro da segunda metade do século XX é marcado não apenas pelas contradições oriundas da massificação cultural e da tecnocratização do mundo, mas, além disso, pelos reflexos da ditadura militar no fragmentado 'todo' social. A repressão política atingiu visceralmente a sociedade, deixando abertas as feridas do autoritarismo que, aos poucos, tornaram-se profundas cicatrizes. Com isso, emerge na arte poética a resistência multifacetada, a tentativa de negar a dominação, de romper as amarras ideológicas. As décadas da segunda metade do século XX foram propícias à multiplicidade constante, à valorização do instável e mutável e à "resistência poética" que, conforme Alfredo Bosi, ora propõe a recuperação do sentido comunitário perdido, ora a melodia dos afetos, ora a crítica da desordem estabelecida.

\begin{abstract}
Na verdade, a resistência cresceu com a "má positividade" do sistema. A partir de Leopardi, Hölderlin, de Poe, de Baudelaire, só se tem aguçado a consciência da contradição. A poesia há muito que não consegue integrar-se, feliz, nos discursos correntes da sociedade. Daí vêm as saídas difíceis: o símbolo fechado, o canto oposto à língua da tribo, antes brado ou sussurro que discurso pleno, a palavra-esgar, a autodesarticulação, o silêncio. [...]

Essas formas estranhas pelas quais o poético sobrevive em um meio hostil ou surdo não constituem o ser da poesia, mas apenas o seu modo historicamente possível de existir no interior do processo capitalista. [...]

A resistência tem muitas faces. Ora propõe a recuperação do sentido comunitário perdido (poesia mítica, poesia da natureza); ora a melodia dos afetos em plena defensiva (lirismo de confissão, que data, pelo menos, da prosa ardente de Rousseau); ora a crítica direta ou velada da desordem estabelecida (vertente da sátira, da paródia, do epos revolucionário, da utopia). (BOSI, 2000, p. 165)
\end{abstract}

É nesse grupo de autores - próximos em razão das metamorfoses por que passaram seus poemas e também eles próprios - que está inserido Ferreira Gullar. Esse escritor maranhense atravessou as décadas de repressão ditatorial brasileira em plena produção literária, chegando a representar um 'perigo' ao governo na década de 1970. Teve, em 1964, as publicações do ensaio "Cultura posta em questão" queimadas por militares. Em 1968, com a assinatura do Ato Institucional $n^{\circ} 5$, é preso. Em 1971, quando morre seu pai, Gullar decide sair da vida clandestina e partir para o exílio. Entre as principais cidades em que passa a residir estão Moscou e Buenos Aires. Em 1975, ano em que é lançado no Brasil Dentro da noite veloz, Vinícius de Moraes traz da Argentina Poema Sujo, gravado em uma fita cassete. Em 1977, o poeta volta ao Brasil e novamente é preso, mas libertado dias depois, com o apoio de amigos. Em 1980, lança Na vertigem do dia, e Poema Sujo é adaptado para o teatro. Sua importância literária cresce à medida que a ditadura dissolve-se e mais obras vão sendo conhecidas e publicadas. 
Em Poema Sujo, doença, pobreza, sensações do submundo urbano são expressas em uma obra "suja de vida". Cada fato cotidiano descrito em meio à narratividade, entrecortada pela fragmentação, é uma denúncia recriada por Gullar:

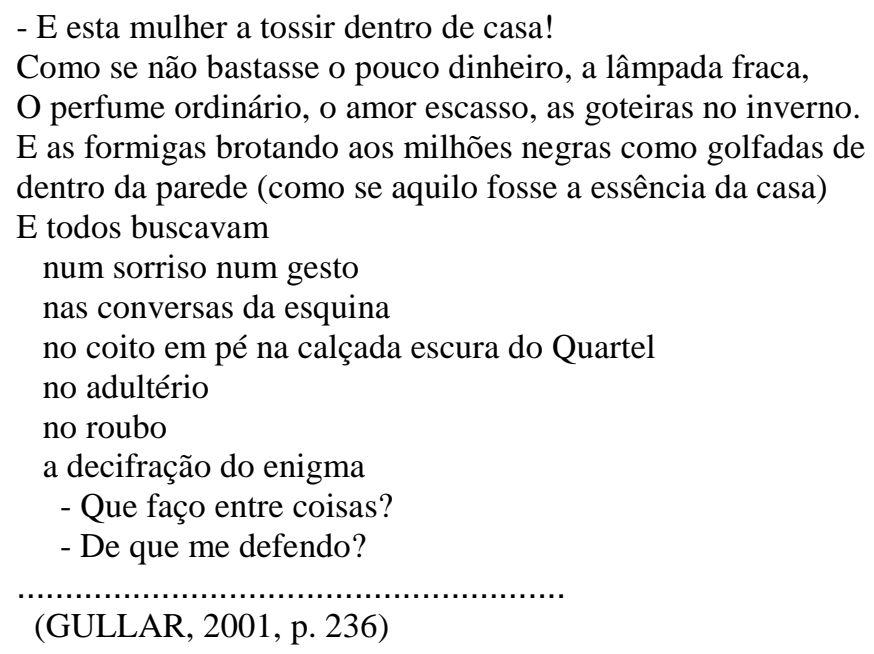

A linguagem, tão arbitrária quanto a vida, envereda pela ruptura sintática, acompanhada de um vocabulário chulo e terreno. $\mathrm{O}$ verso livre, a pontuação não usual, além da disposição assimétrica das palavras no papel fazem com que se observe o paradoxo existente entre a agressividade e a intensa humanização da poética gullariana. Vinícius de Moraes, como crítico, ressalta o valor de Ferreira Gullar ao ler Poema Sujo:

O resultado de tudo isso é que Ferreira Gullar, com "Poema Sujo", acaba de escrever um dos
mais importantes poemas deste meio-século, pelo menos nas línguas que eu conheço; e
certamente o mais rico, generoso (e paralelamente rigoroso) e transbordante de vida de toda a
literatura brasileira. Um poema que, sem omitir nenhuma palavra ou ato considerados feios ou
obscenos pela moral burguesa, carrega uma extraordinária pureza de intenções e de sentido.
Um poema que nada tem de sujo, nesse particular; ou melhor, que é sujo de vida, inhaca
humana, do cheiro acre do amor dos corpos, do fervilhar dos germes da vida e dos vermes da
morte. [...] A recorrência, em Poema Sujo, de temas e palavras encontráveis tanto em A Luta
Corporal como em Dentro da Noite Veloz, mostra bem como, no fundo, apesar das
importantes e sofridas mutações experimentadas - sobretudo no enfoque do fenômeno poético
em si -, soube ele preservar íntegro o humanismo fundamental, o mais belo e puro de sua
essência, o mais íntimo e profundo de sua personalidade. (MORAES, 2004)

A resistência poética dá-se em Gullar, principalmente pela crítica direta ou velada à desordem. O poeta abre caminho pela sátira e pela ironia fumegantes, pela consciência revolucionária que não se compadece com as mazelas do presente, pela poesia terrena, perigosa e comunicante.

Testemunha de uma realidade injusta e dilacerada, cruzada por conflitos e múltiplas experiências culturais, Gullar representou a lucidez frente à poesia e a revolta em um vazio de sentido. Seu percurso literário não se restringiu a um estilo, mas ampliou-se a vários: passou por tendências parnasianas e clássicas, idéias concretistas e neoconcretistas, pela poesia 
popular nordestina, chegando às produções combatentes, ardentemente críticas. A diversificada produção origina-se de um múltiplo escritor - poeta, cronista, crítico, tradutor, teatrólogo, ensaísta, artista - o qual interage dinamicamente em um mundo prismático.

Não há espaço para a poesia ingênua e sublime, ela deve voltar-se à vida terrena e ser uma forma de protesto contra a desumanização crescente, inerente ao mundo capitalista. A impureza está no mais profundo olhar à existência humana, olhar que paira na sujeira da subvida brasileira, na realidade árida do cotidiano, nas intempéries de nosso tempo, como nos mostra o poema "Não há vagas", pertencente ao livro Dentro da noite veloz:

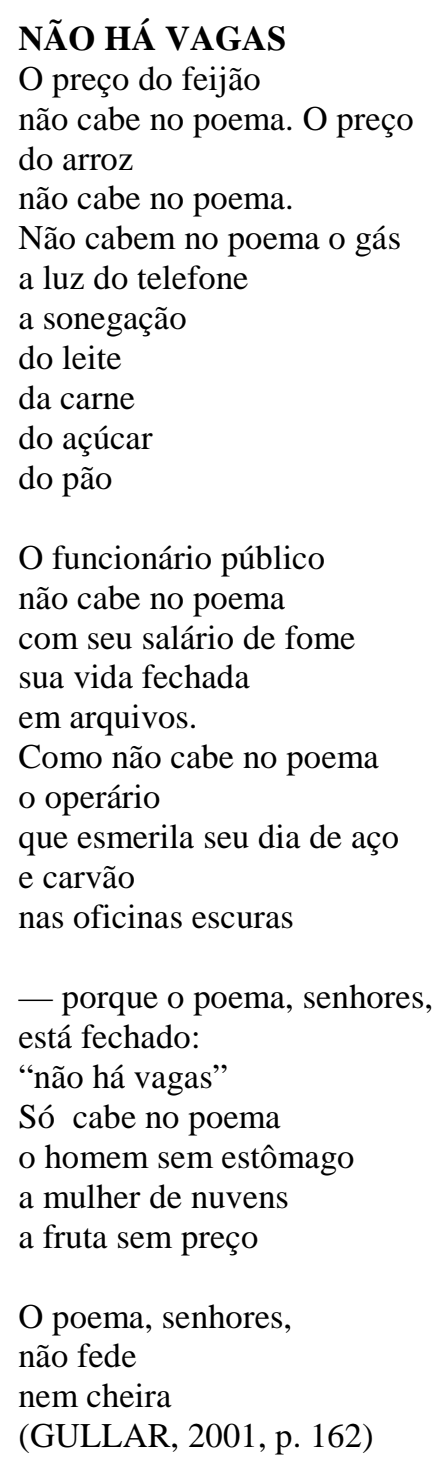

Novamente, a narratividade assola o poema, enveredando pela tentativa de descartar aquilo que fica alheio à realidade grosseira do Brasil. Vale o retrato da podridão social, dos conflitos humanos e da fragilidade econômica e política do país. O espaço do poema precisa ser aberto à vida do arroz com feijão, do funcionário público, do operário, do capitalismo que torna a vida escrava do dinheiro. O poema que esconde a lista de preços, o sofrimento 
daqueles que têm um salário de fome é inútil e desprezível. Gullar escancara sua crítica pela expressão seca, pelo brado irônico, pelas palavras rudes, que ferem, utilizando-se de uma linguagem discursiva, através da qual chega ao dia-a-dia grave, ao submundo da amarga consciência humana.

A resistência poética dá-se em Gullar, principalmente pela negação à desordem, ou à falsa ordem, imposta em tempos incongruentes. Inserido e, ao mesmo tempo, deslocado em uma selva (des)humana, o poeta abre caminho pela sátira e pela ironia fumegantes, pelo olhar revolucionário que não se compadece com os erros de sua época, pela poesia terrena, perigosa e comunicante. Sua não conformidade com a repressão militar trouxe-lhe graves conseqüências, como as perseguições, o exílio e a prisão. Contudo, essas intervenções não foram suficientes para fazê-lo calar-se. Ao contrário, despertaram ainda mais no poeta o desejo da liberdade e a força da escrita:

\section{MAIO 1964}

Na leiteria a tarde se reparte em iogurtes, coalhadas, copos de leite e no espelho meu rosto. São quatro horas da tarde, em maio.

Tenho 33 anos e uma gastrite. Amo a vida

que é cheia de crianças, de flores e mulheres, a vida,

esse direito de estar no mundo, ter dois pés e mãos, uma cara e a fome de tudo, a esperança.

Esse direito de todos que nenhum ato institucional ou constitucional pode cassar ou legar.

Mas quantos amigos presos! quantos em cárceres escuros onde a tarde fede a urina e terror.

Há muitas famílias sem rumo esta tarde nos subúrbios de ferro e gás

onde brinca irremida a infância da classe operária.

Estou aqui. O espelho não guardará a marca desse rosto, se simplesmente saio do lugar ou se morro se me matam.

Estou aqui e não estarei, um dia, em parte alguma.

Que importa, pois?

A luta comum me acende o sangue e me bate no peito como o coice de uma lembrança.

(GULLAR, 2001, p. 169) 
O poema "Maio 1964" é um verdadeiro manifesto contra os desajustes da ditadura militar. O detalhamento da dor, da desilusão, por um homem que vive em um "tempo partido", sem rumo, é concomitantemente a revelação de que a "luta comum" pela vida está no sangue que ainda corre em suas veias. A esperança renasce em meio ao cheiro azedo da injustiça e ao gosto podre da miséria de valores humanos, transformando-se na busca de novos rumos, em meio aos descaminhos da época.

Inconstância e ousadia remetem ao desejo de outra existência, mais livre e viva, pois, assim como a poesia, a esperança não morre. Gullar ultrapassa as fronteiras literárias com sua produção poética, semeando constantemente a esperança em momentos de perseguição política, de crise cultural e de angústias sociais.

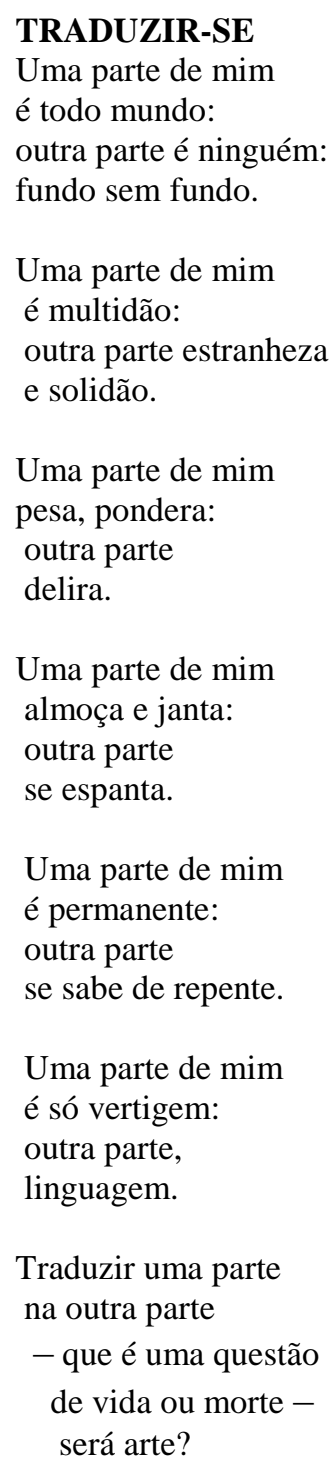

O poema "Traduzir-se", publicado em 1980 em Na vertigem do dia, é a forma do desencontro íntimo do "eu-lírico", consequiência de sua fragmentação interior. O ser que se 
desconhece carece de tradução, pois é um poço de contradições. Ele é o microcosmo de um mundo despedaçado, no qual a vida e a morte, a solidão e a multidão, a individualidade e a outridade, a razão e os sentimentos, o cotidiano e o inusitado, o perene e o mutável, a linguagem e a vertigem, tal como cacos, juntam-se para formar o mosaico irregular do mundo. A arte torna-se essa tentativa de tradução dos enigmas de nosso tempo, nem sempre elucidáveis. Sua função social emerge, muitas vezes, de questionamentos sem respostas, como os que percebemos nos poemas aqui citados.

A impostura da poesia relaciona-se com a ousadia e a liberdade. Seu perigo e sua impureza remetem às funções sociais do poeta moderno - indagador, filósofo, profeta - que, muitas vezes, desorganiza o mosaico ao seu redor. A contrariedade do mundo força-o a ser crítico e a fazer de sua criação poética um modo de resistência. Octavio Paz reconhece o mundo heterogêneo e desafiador no qual vivemos, que nos faz buscar o outro, a fim de repensarmos sobre a identidade individual e a imagem social. "A dispersão da imagem do mundo em fragmentos desconexos resolve-se em uniformidade e, assim, em perda da outridade. [...] A outridade é a percepção de que somos outros sem deixarmos de ser o que somos." (PAZ, 1982, p. 324). Gullar soube muito bem, com toda sua singularidade, expor a sujeira do país, posicionando-se politicamente em uma época conturbada da história nacional. Nas produções desse poeta, encontramos experiências, ganhos, perdas, angústias e esperanças do povo brasileiro. Portanto, é a problematização do ser humano que consolida a resistência poética de Ferreira Gullar: "Pretendo que a poesia tenha a virtude de, em meio ao sofrimento e ao desamparo, acender uma luz qualquer, uma luz que não nos é dada, que não desce dos céus. Mas que nasce das mãos e do espírito dos homens.” (GULLAR, 2001, p. 1)

\section{Referências}

BOSI, Alfredo. Céu, inferno. 6.ed. São Paulo: Ática, 1988. . O ser e o tempo da poesia. 6.ed. São Paulo: Companhia das Letras, 2000.

GULLAR, Ferreira. Toda Poesia. 11.ed. Rio de Janeiro: José Olympio, 2001. - [s.d.] Disponível em: http://www2.uol.com.br/ferreiragullar/poesia/. Acesso em 09 out. 2004.

MORAES, Vinicius de. Poema sujo de vida. In: GULLAR, Ferreira. [s.d.] Disponível em: http://www2.uol.com.br/ferreiragullar/poesia/. Acesso em 09 out. 2004. 
PAZ, Octavio. O arco e a lira. Rio de Janeiro: Nova Fronteira, 1982.

. Os filhos do barro: do Romantismo à vanguarda. Rio de Janeiro: Nova Fronteira, 1984.

STEINER, George. Linguagem e silêncio: ensaios sobre a crise da palavra. São Paulo: Companhia das Letras, 1988. 